\title{
CONCEPTUALISING THE PHD AS PREPARING FOR ACADEMIC PRACTICE IN GEOGRAPHY
}

Nick Hopwood, School of Education, University of Technology Sydney, PO Box 123, Broadway NSW 2007, Australia. Email:nick.hopwood@uts.edu.au Lynn McAlpine, Oxford Learning Institute, Littlegate House, 16/17 St Ebbe's Street, Oxford, OX1 1PT Email:lynn.mcalpine@learning.ox.ac.uk

\begin{abstract}
This paper situates the geography $\mathrm{PhD}$ within the broader context of doctoral education. It addresses questions relating to the $\mathrm{PhD}$ as preparation for future academic work. Theoretical and practical ideas are woven through a discussion of the work of the Centre for Excellence in Preparing for Academic Practice, at the University of Oxford (UK). The Centre initiated wide-ranging reforms and has had lasting impacts, with a philosophy of remaining sensitive to disciplinary context. The paper argues that Cultural Historical Activity Theory (CHAT) is a useful lens for understanding challenges in contemporary doctoral education, and responses to them. Key concepts are outlined, and a worked example provided, drawing from the Centre's work. Connections are made with relevant initiatives specific to geography.
\end{abstract}

Keywords

Academic practice, doctoral education, $\mathrm{PhD}$, activity theory

\section{Introduction}

The Centre for Excellence in Preparing for Academic Practice ${ }^{1}$ had amongst its goals a remit to enhance the professional development experiences at the University of Oxford of doctoral students and postdoctoral research staff (those with PhDs working on their own or other grants) who seek academic careers. The Centre ran from 2005-2010, but its values and activities live on in the approaches to academic practice and doctoral education across Oxford and beyond. This

*N. Hopwood

School of Education, University of Technology, Sydney, Broadway, NSW 2007, Australia

e-mail: nick.hopwood@uts.edu.au 
paper reports on key aspects of the approach taken, reflecting on the theoretical ideas and practical undertakings that underpinned its success and legacy.

The Centre was housed only metres from the School of Geography founded by Halford Mackinder over a century ago. Thus, we speak from a position of privilege, a place where geography as a discipline is firmly established, and where issues relating to doctoral education have been the focus of high-level reform at both national and institutional levels. At the time there were concurrent policy agendas within Oxford (led by the Pro Vice Chancellor for Education), linked to UK-wide initiatives around research skills training and teaching quality audit processes. Despite this, there remain ongoing struggles within disciplines, institutions, departments, and at a national policy level to respond to the challenges of global mobility and competition, social justice, the role of knowledge in the economy, and the need to question the purpose of the doctorate (eg. Roberts 2002; Park 2007).

The institutional focus of the Centre's work was initially on establishing discipline-specific teaching development programs. Subsequently, staff from the Centre worked with departments and faculties to stimulate new provisions which would better reflect the diversity of academic working roles - going beyond teaching and research to address institutional, disciplinary and community service. There were challenges, particularly given increasing time pressures on doctoral students and their institutions (e.g., national policies expecting completion in three years), such that wider professional development is seen by some as competing with thesis completion. Our response was to promote a view of the doctorate as a broad professionally formative experience, comprising learning in a number of dimensions which may complement rather than compete with each other. The legacy of this is maintained through the ongoing devolved work across the University's Faculties, Departments and Schools, including academic advisors and preofessional development trainers in each disciplinary cluster, training offered by the Learning Institute and other services, (e.g., the University Careers Service), and coordinated by the University Skills Group which reports to a senior committee, Graduate Panel, chaired by the Pro Vice Chancellor (Education). 
The Centre also worked at a national level, presenting its discipline-based model of engagement. We sought to stimulate alternative ways of thinking about the $\mathrm{PhD}$ based on holistic conceptions of academic practice, and a principle of linking developmental opportunities to envisaged future practices. Again we faced challenges - a strong policy focus in the UK over this period has been based on a different set of values and priorities (the so-called Roberts or skills agenda, which focused on generic skills development). However the response to our initiative across the sector was highly positive, with disciplinary bodies and institutions taking up academic practice as an agenda, with changes evident from personal and departmental practices through to larger scale discipline-wide engagement with these issues.

In this short paper we present two problems that we encountered and describe how concepts from sociocultural theory helped us to move forward practically. Sociocultural perspectives have close links to the work of Russian psychologist Lev Vygotsky and in general seek to explicate relationships between what people do and the cultural, institutional and historical situations in which such activity occurs (Wertsch et al. 1996). A central principle holds that to understand activity one must understand the object (purpose, goal) to which it is oriented.

\section{Dealing with complex contexts in doctoral reform}

A key challenge we faced in our work at the institutional level involved identifying instances where students were frustrated in their development as academics and finding ways to address those frustrations. In this respect we found Cultural Historical Activity Theory (CHAT), a specific body of work within the broader sociocultural tradition, particularly useful, as we had earlier in a related analysis (Beauchamp et al., 2009).

CHAT developed in recent decades as a means to apply many of Vygotksy's ideas about individual development to issues of institutional change (Engeström 1987). It adopts the perspective of the subject (the protagonist, perhaps the doctoral student) while being constantly mindful of the object of their activity (the thing that is striven for, for example, a successful transition from $\mathrm{PhD}$ to academic 
work), and the tools and concepts at their disposal. However it adds three additional features which make it easier to apply this kind of thinking at an institutional scale: division of labour (the different roles undertaken by different people which have a bearing on particular activity, such as supervisors/advisors, committees, administrators, support staff, examiners etc.); community (the wider group of people brought together around the shared object, such as departmental or disciplinary peers); and rules (both formal/explicit, and informal/implicit, for example degree awarding criteria, norms for social interaction within a particular department). Collectively these form what is termed an activity system. In seeking to stimulate change, one can look at the interactions across the system to identify aspects that are in tension with each other, and focus reform on seeking to alleviate those tensions (Engeström 1999).

By conceiving doctoral education as an activity system we could define a focus for reform by identifying tensions or contradictions between different components of it. The tradition of TA-ship is not as common in the UK as in many North American institutions, and many more doctoral students wanted to teach than had the opportunity to do so, and those who were teaching often felt under-supported in this role. We interpreted this as a tension between students' objects (developing not only as researchers, but as higher education teachers too) and the division of labour (limited teaching opportunities), rules (unfair and opaque allocation of those opportunities, focus by supervisors on finishing the degree) and community (lack of social venue for or cultural practice of discussion of teaching and provision of pedagogic support). In working with departments and faculties these issues were addressed by seeking to create teaching-focused communities for doctoral students through reading groups and workshops, changing the rules by making the process of recruiting doctoral students to teaching positions more transparent, and promoting the value of teaching with supervisors.

To evaluate our progress we collected evidence that would indicate whether the tensions we identified had been alleviated. Overall there was considerable success in establishing communities within and across departments, and signs indicate that rules were beginning to change, with teaching registers linked to attendance at training being used in appointment processes. However other rules have proved 
less tractable, particularly those imposed externally regarding $\mathrm{PhD}$ completion times (see Hopwood and Stocks 2008).

\section{A specific example of theoretically informed development work}

The focus on 'doing research' in doctoral education often leaves students illprepared for the diversity of roles they would be expected to undertake if they continue working as academics after graduation. This was the driving force behind a number of reform initiatives in the United States: Preparing Future Faculty (Wulff and Austin 2004); Re-envisioning the PhD (Nyquist et al. 2004); The Responsive PhD (WWNFF 2005); and The Carnegie Initiative on the Doctorate (Walker et al. 2008). If we are preparing doctoral students for academic practice, this preparation should reflect the nature of that practice and incorporate development opportunities relating to teaching, service, administration and outreach. It should also help students develop an explicit understanding of the practice they are being prepared for (Austin 2002).

The challenge for us was then to find a framework for translating these needs into concrete practices. In doing so we applied concepts of third spaces as conceived within a sociocultural framework (and distinct from Soja’s postmodern thirdspace notion). Third spaces arise when people come to work together who would not normally have done so, and when this joint effort is focused on a shared object or purpose (Gutierrez et al. 1995; Tuomi-Grohn et al. 2003). In bringing together new constellations of people around shared but often overlooked ideas, third spaces can create a unique and productive venue for challenging established ways of thinking and for stimulating collaboration across what may often be entrenched silos in which different interests compete rather than complement each other.

We developed and ran a number of day-long workshops which implemented third spaces in practice. Each focused on a particular discipline or disciplinary cluster and was attended by doctoral students, early career academics, senior faculty, and academic developers, and was open to participants from any UK university. In total, we worked with students, early career and senior faculty from over seventy institutions and twenty-four disciplines. The coming together of people with such diverse roles and institutional backgrounds is not a common feature of everyday 
academic life, although conferences may offer similar opportunities. These workshops combined a diversity of stakeholders with an explicit and novel object: the nature of academic practice in particular discipline(s).

In initial plenary talks, experienced academics shared the diversity of roles and the dynamism of their careers over time; these feed into group discussions in which experiences across roles and institutions are shared, and areas for improvement identified (see McAlpine and Hopwood 2009). Evaluative evidence suggests that regardless of role, participants left these events with a combination of new personal agendas and with issues to raise with their own institutions with a view to broader reform (tensions across the system), new communities and new tools and resources. Since initiating these events, we have witnessed disciplinary bodies and associations take up this model to engage their memberships around academic practice themes. Similar workshops have since been offered in universities in Australia, and the logic underpinning them has informed larger conferences for aspiring academics, such as the 'Academia - A Scholarly Life' event hosted by the University of Western Sydney in 2011.

\section{Academic practice in geography}

What might be involved if geography as a discipline took more ownership of doctoral development in teaching and other aspects of academic practice? In the United States geography benefits from the strength of the Association of American Geographers within the community and the numerous graduate-focused opportunities and initiatives it sponsors². The Geography Faculty Development Alliance $^{3}$, runs summer residential workshops and other activities throughout the year, offering crucial support for new geography faculty, particularly in relation to their teaching roles. It constitutes a discipline-specific, discipline-owned and cross-institutional example of reform which creates an opportunity for academics to discuss and learn about aspects of academic work that may have been overlooked in their doctoral experience. What would the Geography Doctoral Development Alliance look like or seek to achieve?

One of our events described above was run in conjunction with the UK Subject Centre for Geography, Earth and Environmental Sciences ${ }^{4}$ (GEES). Here it 
became apparent that geographers face what is perhaps a unique challenge in rethinking the $\mathrm{PhD}$. Academic life for the lab-based geomorphologist may be very different from that of the postmodern cultural geographer. To what extent does the heterogeneity found within geography present special problems for professional development in the discipline? Would, for example, future geomorphologists better be served by being differently and separately prepared for distinct geomorphological academic practices? These questions strike at the heart of the discipline's problematic: What ties geographers together? What is distinctive about academic practice in geography? Bringing these issues into the question of doctoral reform is vital, as it is through the next generation of doctoral graduates that the shape, frontiers and value of the discipline will be defined.

\section{Final thoughts}

What lessons have we learned from our experience? What would we encourage others seeking to enhance doctoral experiences in geography to consider? While our discipline-based model created diversity and thus some complexity in dealing with multiple contexts, we found in practice what the sociocultural perspective urges us to recognise theoretically: that the cultural, social and historical settings of any activity (ongoing academic practice, doctoral education, reform efforts) are crucial. We argue that attending to this involves more than responding to local practicalities and institutional politics; it requires a conceptual understanding of how the individual and the local relate to their wider environments and one which accounts for many of the social and cultural elements of institutional life.

CHAT is particularly helpful in this respect, and we would encourage others to try to identify and understand foci for change by thinking in terms of tensions between students' objects and other parts of an activity system. The same set of conceptual tools can then be used to tie evidence of impact to a reform agenda that strikes at fundamental rather than surface issues.

We present third spaces as a useful tool that might lead readers to conceive concrete activities and practical outcomes of a very different nature. We urge readers to think of their own contexts and list the different groups of people who have an interest in or bearing upon particular aspects of doctoral reform. Under 
what circumstances and in which venues do or might these people come together? What objects or shared ideas or purposes could provide a useful framing for discussion or collaborative work among these groups?

In drawing explicitly on theoretical underpinnings of our work, we seek to share not the specifics of our efforts and their outcomes, but the ideas lying behind them. The same practical interventions may not apply elsewhere - context will often shape what is needed and what works - but the socioculturally informed approach to change is, we suggest, likely to prove fertile more broadly.

\section{Foototes}

${ }^{1}$ The Centre for Excellence in Preparing for Academic Practice was one of 74 Centres for Excellence in Teaching and Learning (CETLs), funded by the Higher Education Funding Council for England from 2005-2010. For more information about the story of the CETL, see http://www.cetlrecord.ox.ac.uk/. The CETL also produced an extensive suite of learning and decvelopment resources for research students and those supporting them, see http://www.apprise.ox.ac.uk/. Both authors worked in the Centre at the time.

${ }^{2}$ For example, the Enhancing Departments in Graduate Education in Geography (EDGE) research and action project (http://www.aag.org/edge), and opportunities for graduates to become involved in service / organisation at the Association's Annual Meeting

${ }^{3}$ See http://www.colorado.edu/geography/gfda/gfda.html

${ }^{4}$ While all the subject centres have now been discontinued due to budget cuts, similar resources for each field (primarily teaching-focused) are expected to be made available by the UK Higher Education Academy in the coming year.

\section{References}

Austin, A. E. (2002) 'Preparing the next generation of faculty: graduate school as socialisation to the academic career'. The Journal of Higher Education, 73(1), 94-122.

Beauchamp, C., Jazvak-Martek, M., \& McAlpine, L. (2009). Studying doctoral education: using Activity Theory to shape methodological tools. Innovations in Education and Teaching International, 36 (3), 265-277. 
Engeström, Y. (1987) Learning by expanding: an activity-theoretical approach to developmental research. (Orienta-Konsultit, Helsinki)

Engeström , Y. (1999). 'Activity theory and individual and social transformation'. in Engeström Y, Miettinen R \& Punamaki R L (eds.), Perspectives on activity theory (Cambridge University Press, Cambridge) 19-38.

Gutierrez, K., Rymes, B., \& Larson, J. (1995). 'Script, counterscript, and underlife in the classroom: James Brown versus Brown v. Board of Education'. Harvard Educational Review, 65(3), 445-471.

Hopwood, N., \& Stocks, C. (2009). 'Research and development for early career academics: encouraging signs, but are we talking past each other?' International Journal for Academic Development, 14(3), 169-171.

McAlpine, L., \& Hopwood, N. (2009). 'Third spaces': a useful developmental lens?’ International Journal for Academic Development, 14(2), 159-162.

Nyquist, J. D., Woodford, B. J., \& Rogers, D. L. (2004). Re-envisioning the PhD: a challenge for the twenty-first century. In D. H. Wulff \& A. E. Austin (eds.), Paths to the professoriate: strategies for enriching the preparation of future faculty (Jossey-Bass, San Francisco), 194-216.

Park, C. (2007). Redefining the doctorate. (Higher Education Academy, York)

Roberts, G. (2002). SET for Success: final report of Sir Gareth Roberts' Review. (HM Treasury, London)

Tuomi-Grohn, T., \& Engeström , Y. (2003). 'Conceptualising transfer: from standard notions to developmental perspectives' in Tuomi-Grohn T \& Engeström Y (Eds.), Between school and work: new perspectives on transfer and boundary-crossing (pp. 19-38). (Pergamon, Oxford)

Wertsch, J., del Rio, P., \& Alvarez, A. (1996). 'Sociocultural studies: history, action and mediation'. in Wertsch, J P. delRio, P \& Alvarez A (eds.), Sociocultural studies of mind (Cambridge University Press, Cambridge) 132.

Wulff, D. H., \& Austin, A. E. (Eds.). (2004). Paths to the professoriate: strategies for enriching the preparation of future faculty. (Jossey-Bass, San Francisco)

WWNFF (Woodrow Wilson National Fellowship Foundation). (2005). The Responsive PhD: innovations in US doctoral education. (Woodrow Wilson National Fellowship Foundation, Princeton, NJ) 
